\title{
Idiopathic Dilatation of Pulmonary Artery with Effort Angina
}

\author{
${ }^{1}$ Dr.MalleshKariyappa.MD.,DNB(Ped).,(DM). ${ }^{2}$ Dr.Nagesh.MD., \\ DM(cardiology)., ${ }^{3}$ Dr. Srinivas B C.MD.,DM.(cardiology), \\ ${ }^{3}$ Dr. Manjunath C N.MD.,DM(cardiology). \\ Department of cardiology, SriJayadeva Institute of Cardiology, Bangaluru,Karnataka, India.
}

\begin{abstract}
Idiopathic pulmonary artery dilatation is a rare vascular abnormality with an incidenceof $0.007 \%$ in autopsy. Diagnosis is established by excluding diseases that induce pulmonary arterialenlargement. Dilatation of the pulmonary artery is complicated with mildpulmonary valve stenosis. Here, we present a rare caseof idiopathic dilatation of the pulmonary artery with mildvalvularpulmonary stenosis which presented with effort angina and was diagnosed using echocardiography and cardiac catheterization.

(key words-idiopathic pulmonary artery dilatation with pulmonary stenosis, idiopathic pulmonary artery dilatation with effort angina)
\end{abstract}

\section{Case summary}

36 years old female patient born of non consanguineous marriage from low socioeconomic status having no significant past history of medical illness presented with exertionalchest pain of 15 days duration,located in midline, heaviness type , moderate in intensity, non radiating, lasting more than 5- 10 minutes, subsiding with taking rest. There was also history of exertional breathlessness (NYHA -II) of 15 days duration. No history of cough, fever, palpitation, giddiness, breathlessness in lying down positionor at night.

Pulse rate-84/min, respiratory rate-15/min,BP-126/80mHg.saturation-98\% in room air.There was no pallor ,icterus,cyanosis,pedal edema.JVP -was not elevated. Apical impulsewas located in 5th intercostals space medial to mid clavicular line, normal character. Precordial pulsations in left second intercostal space, left 3rd- 4th intercostals spaces.Left second space was dull to percuss.Ejection click with ejection systolic murmur was heard in the same area. Ejection click was louder during expiration.ESM was of grade 2/6,high pitched,crescendo decrescendo in nature. Respiratory system, gastro intestinal system, central nervous system examination was normal.

Patient's investigations were; Hemoglobin-13gm/dl,total count-10200/miclit, neutrophils-62\%, ,lymphocytes-30\%, eosinophil-4\%, monocyes-5\%,basophils-1\%. ESR-12mm.Natriuretic peptide (BNP) and antineutrophil cytoplasmic autoantibody (ANCA) levels were within normal limit, and there was no evidence of infectious diseases such as tuberculosis or syphilis.

X-Ray chest revealed mild cardiomegaly of right ventricular type ,mild right atrial dilatation, massive enlargement of main pulmonary artery with normal pulmonary vascular markings.

Echocardiographic findings were; enlarged enlarged main pulmonary artery $(3.8 \mathrm{cms})$, right pulmonary artery $(1.9 \mathrm{cms})$, left pulmonary artery $(1.8 \mathrm{cms}$ ) in parasternal short axis (ULN is $2.1 \mathrm{~cm}$ for MPA and $1.4 \mathrm{~cm}$ for LPA and RPA).. Right ventricle dimension was $2.1 \mathrm{~cm}$. Right ventricle free wall thickness was $5 \mathrm{~mm}$. There was no intracardiac and extracadiac shunt. Left ventricular function was normal. The right descending pulmonary artery measured $17 \mathrm{~mm}$ on the chest radiograph; the upper limit of normal is $16 \mathrm{~mm}$.

Cardiac catheterization was done through right femoral vein/ right femoralartery approach. RV angiogram showed trabeculated right ventricle with normal pulmonary valve and massively dilated main pulmonary artery . Hemodynamic data were as follow:

\begin{tabular}{|l|l|l|}
\hline Site & pressure & saturation \\
\hline SVC & & $74 \%$ \\
\hline RA & Mean- $4 \mathrm{mmHg}$ & $78 \%$ \\
\hline RV & $48 / 7 \mathrm{mmHg}$ & $82 \%$ \\
\hline PA & $30 / 8(18) \mathrm{mmHg}$ & $79 \%$ \\
\hline LV & $120 / 12 \mathrm{mmHg}$ & $98 \%$ \\
\hline AO & $120 / 84(108) \mathrm{mmHg}$ & $98 \%$ \\
\hline
\end{tabular}

There was no significantstep up in saturation suggestive of intra cardiac as well as extra cardiac left to right shunts. Coronary angiogram revealed normal coronaries. Hence, the diagnosis of Idiopathic pulmonary artery dilatation was made. 


\section{Discussion.}

Idiopathic dilatation of the pulmonary artery is a rare diseasefirst described byWessler and Jaches [1]. The incidence of this disease is 6 cases per 1000 cases of congenital cardiac disorders [2]. Greene et al In 1949 [3] proposed thefollowing diagnostic criteria for this condition: (1) simple dilatation of the pulmonary trunk; (2) absence of intraorextra-cardiac shunts; (3) absence of chronic cardiopulmonary disease; (4) absence of arterial disease such assyphilis, atherosclerosis, or arteritis, Deshmukh et al In 1960 [4] added the fifth criterion, i.e. normal pressure in the right ventricle and pulmonary artery.Only 5 cases of idiopathic pulmonary aneurysms with mild pulmonary valve stenosis have been reported to date(5). The pressure gradients of all five patients wereLower than $20 \mathrm{mmHg}$.as in our case . Van Buchem et al. [6] reported that the normal diameter of the pulmonary artery ranged from 22 to $33 \mathrm{~mm}$. Post stenotic dilatation was observed when the pressure gradient wasmore than $25 \mathrm{mmHg}$. In contrast, patients with idiopathic pulmonary aneurysms showed remarkably dilated pulmonaryarteries in the absence of pressure gradients $(\leq 5 \mathrm{mmHg})$. Although a mild pressure gradient might increase pulmonary artery enlargement, it was not considered as one of the main reasons for the marked pulmonary artery dilatation. In 1987, Futagami et al. [7] reported 60 Japanese cases of idiopathic dilatation of the pulmonary artery. Pressure data of 39 of thesepatients were analyzed . A pressure gradient of $\leq 5 \mathrm{mmHg}$, considered as noor trivial pressure gradient was observed in $64 \%$ of the 39patients, but $36 \%$ of patients showed mild pressure gradients $(6-22 \mathrm{mmHg}$ ) between the right ventricle and the pulmonary artery. These data suggest that a mild pressure gradientmight often be seen in patients with idiopathic pulmonary aneurysms. CMR may be used in the diagnosis of pulmonary artery aneurysms in case of doubt in echocardiography as a non invasive modality with advantages of measuring the precise diameter of theaneurysm ,no use of contrast agents, evaluation of the right ventricular outflow tract, no radiation exposure and quantifypressure gradient of pulmonary artery stenosis.(5).It is the preferred option for combined use with echocardiography in the diagnosis and follow-up of patients with IDPA.

Characteristic pattern is found on analysis of the phonocardiogram; it consists of a normal first heart sound, a systolic click, a faint or absent pulmonic systolic murmur, wide splitting of the second heart sound which is usually fixed, and occasionally a diastolic murmur at the pulmonary area. This distinctive pattern may prove to be of value in the diagnosis of idiopathic dilatation of the pulmonary artery(8). Pulmonary insufficiency observed in $80 \%$ of cases,, which was not seen in our case. Exertional chest pain observed in our case could be due to massive dilatation of pulmonary artery with increased wall stress which is pronounced during effort.

No data are available for the long-term prognosis ofpatients with idiopathic dilatation of the pulmonary arterywith mild pulmonary artery stenosis.More so with symptomatic cases,although there are case reports of asymptomatic pulmonary dilatation detected on routine examination in sixth decade (10). Idiopathic pulmonary artery dilatation is clearly a benign and non-progressive condition incontrast to our case . Any rapid progression of symptomswith apparent idiopathic dilatation of pulmonary artery may haves an arteritis or connective tissue disorder. Eventhe asymptomatic cases need to be followed up for the development of connective tissue diseases.

\section{Conclusions:}

Idiopathic pulmonary artery dilatation is rare disease after exclusion of conditionscausing pulmonary artery dilatation.Any patient with apparent diagnosis of idiopathic pulmonary hypertensionneeded to be followed up for long time to know benign course. Any rapid course ofsymptoms should be evaluated for possible infectious and inflammatory diseases, although occasionally the manifestation of idiopathic pulmonary artery dilatation.

\section{References}

[1]. Wessler H,Jaches L. Clinical roentogenology of disease of thechest. Troy, New York: The Southworth Company; 1923. p. 26.

[2]. Abbott ME. Atlas of congenital cardiac disease. New York:American Heart Association; 1936. p. 65.

[3]. Greene DG, Baldwin EF, Baldwin JS, Himmmelstein A, RobCE, Cournand A. Pure congenital pulmonary stenosis and idiopathiccongenital dilatation of the pulmonary artery. Am J Med1949;6:24—40.

[4]. Deshmukh M, Guvenc S, Bentivoglio L, Goldberg H. Idiopathicdilatation of the pulmonary artery. Circulation1960;21:710-46.

[5]. TomiharuNiida (MD), Takayuki Kitai (MD), KikuoIsoda (MD, PhD), Takeshi Adachi (MD, PhD), Fumitaka Ohsuzu (MD, PhD, FJCC) A case of idiopathic dilatation of the pulmonaryartery with mild subvalvular pulmonary stenosis. Journal of Cardiology Cases (2011) 3, e53-e56

[6]. Van Buchem FS, Nieveen J, Marring W, Van Der Slikke LB.Idiopathic dilatation of the pulmonary artery. Dis Chest1955;28:326-36.

[7]. Futagami Y, Yada T, Konishi T, Iwata J, Hamada M, Nakano T, etal. Idiopathic dilatation of the pulmonary artery: a case reportand review of 59 cases in Japan. Mieigaku 1987;31:425-32 (InJapanese).

[8]. James N. Karnegis, Yang Wang .The American Journal of Cardiology, Volume 14, Issue 1, July 1964, Pages 75-78

[9]. Howard W. Ramsey, Angel de la Torre, Joseph W. Linhart, L.JeromeKrovetz, Gerold L. Schiebler, J.Russell Green JrThe American Journal of Cardiology, Volume 20, Issue 3, September 1967, Pages 324-330

[10]. Emanuel Goldberg, IsadoreKatz..The American Journal of Cardiology, Volume 9, Issue 4, April 1962, Pages 619-625 